\title{
The Biomechanical Aetiology of the So-Called Idiopathic Scoliosis. The Role of Gait and Standing at "Ease" on the Right Leg in the Development of the Deformity
}

\author{
Tomasz Karski ${ }^{1}$, Jacek Karski ${ }^{2}$ \\ ${ }^{1}$ Vincent Pol University, Lublin, Poland \\ ${ }^{2}$ Paediatric Orthopaedic and Rehabilitation Department, Medical University, Lublin, Poland \\ Email: tmkarski@gmail.com, t.karski@neostrada.pl, jkarski@vp.pl
}

Received November 27, 2013; revised December 25, 2013; accepted January 3, 2014

Copyright (C) 2014 Tomasz Karski, Jacek Karski. This is an open access article distributed under the Creative Commons Attribution License, which permits unrestricted use, distribution, and reproduction in any medium, provided the original work is properly cited. In accordance of the Creative Commons Attribution License all Copyrights (C) 2014 are reserved for SCIRP and the owner of the intellectual property Tomasz Karski, Jacek Karski. All Copyright (C) 2014 are guarded by law and by SCIRP as a guardian.

\section{ABSTRACT}

The article presents the biomechanical etiology of the so-called idiopathic scoliosis. The research was conducted in the years 1985-2013, but the importance of the observations connected with the so-called idiopathic scoliosis were completed in $2007(4,5,6,7,8,9)$. All types of spine deformity are proved to have a connection with gait and with standing "at ease" on the right leg. Every type of scoliosis begins to develop at the age of 2 - 3. The article provides short information about new screening tests and new exercises in the course of causal prophylaxis and treatment.

\section{KEYWORDS}

\section{Biomechanical Aetiology of Idiopathic Scoliosis; Gait and Standing “At Ease” on the Right Leg in the Development of the Deformity}

\section{Introduction}

The article provides information concerning the biomechanical aetiology of the so-called idiopathic scoliosis [adolescent idiopathic scoliosis-AIS] (T. Karski, 19852007, first publication in 1996). The development of scoliosis is connected with the asymmetry of hip movement in gait and with habitual standing "at ease" only or mostly on the right leg. During the gait, due to the restriction of movement of the right hip, a compensatory movement is transmitted to the pelvis and to the spine causing scoliosis. Another influence is connected with permanent standing "at ease" on the right leg. Other influences are connected with abnormalities of Central Nerve System (CNS) and they are extension contracture of spine, anterior tilt of pelvis and laxity of joints.

\section{Material}

In 2012, the material reached 1950 cases (from the Orthopaedic Department and the Out-Patient Clinic). The age of patients varied from 3 to 50 . In the years 19852005 more than $20 \%$ of patients suffered from iatrogenic deformity either consequent to a corset conservative treatment in scoliosis or due to previous therapy exploiting harmful exercises. In the last 8 years the new ideas concerning the so-called idiopathic scoliosis have been popularised in Poland and the number of cases treated with harmful exercises significantly decreased.

\section{The Biomechanical Aetiology}

To explain the biomechanical aetiology we must remember about the three asymmetries causing the development of scoliosis:

1) The asymmetry of the movement in the hips (Figures $1(a)$ and (b));

2) The asymmetry of the movement in pelvis and spineleft versus right side in gait;

3) The asymmetry of the time while standing "at ease" on the left versus the right leg-more time on the right leg. 


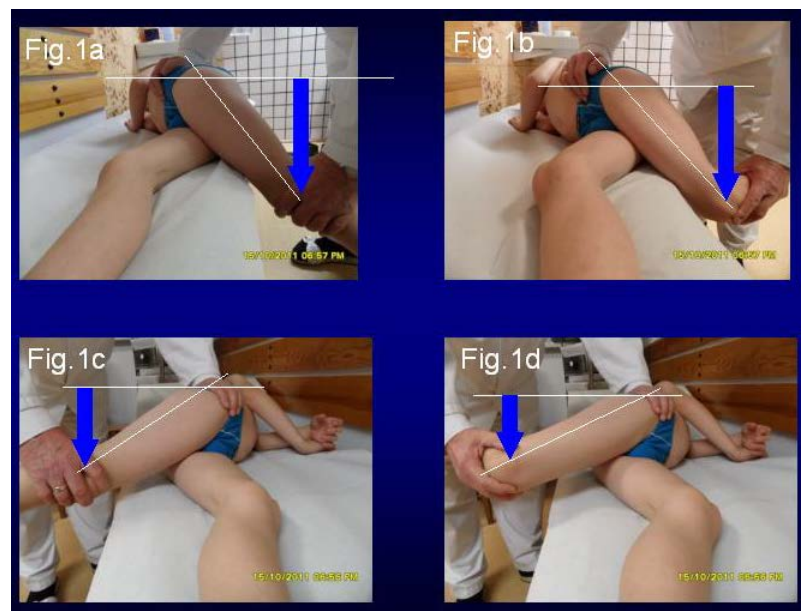

Figure 1. Asymmetry of movement of hips (primary Syndrome of Contractures). Two methods of examination. Adduction of hips test in straight position of the joints-when performed in extension of the knee and in flexion of the knee it proves to be more sensible.

The asymmetry of movement of the hips is connected with "Seven Contractures Syndrome" (Figures 2(a)-(c)) described by Professor Hans Mau from Tübingen in Germany in 1960s (in German Siebenersyndrom) and then further explained (Lublin, T. Karski) in the context of the spine in the years 1985-2007 [1-15].

The consequential development of the spinal deformity is as follows:

1) Every type of scoliosis depends on the Model of Hips' Movement (MHM) (T. Karski, 2006);

2) When the movement of hips is symmetrical — there is no pathological influence on spine during walking/gait and the is also symmetry of time standing on left/right leg. In such situation, develop never scoliosis (Figure 3);

3) The asymmetry of the movement of hips in all cases of the so-called idiopathic scoliosis bases on the limited adduction, limited internal rotation and limited extension in the right hip. This phenomenon explain "the lest sided Syndrome of Contractures";

4) In gait, there is a limited movement of the right hip which is transmitted to pelvis and spine as a compensatory process and "enlarges" the movement in the spinal region. Consequently, there occurs a permanent distortion of the inter-vertebral joints, a rotation deformity and later stiffness of the spine. The asymmetry of the movement of hips in gait also causes a load asymmetry "in time" on both sides—-left and right—and further, a gradual development of scoliosis;

5) The permanent standing "at ease" on the right leg (the right hip is more stable [!]) starts and widens the curves-first, lumbar left convex and in II/B epg (see farther/next text) thoracic right convex curves;

6) The following influences connected with gait and with standing on the right leg gives: three groups and

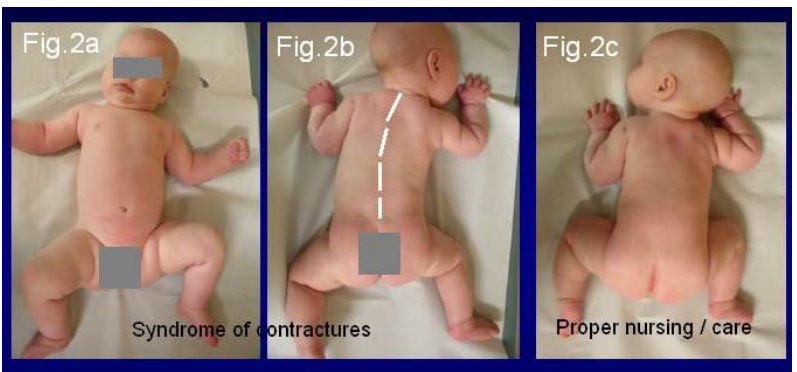

Figure 2. Example of asymmetries in Syndrome of Contractures: Child with the-asymmetry of head, neck, pelvis and hip position and differences of movements (during examination).

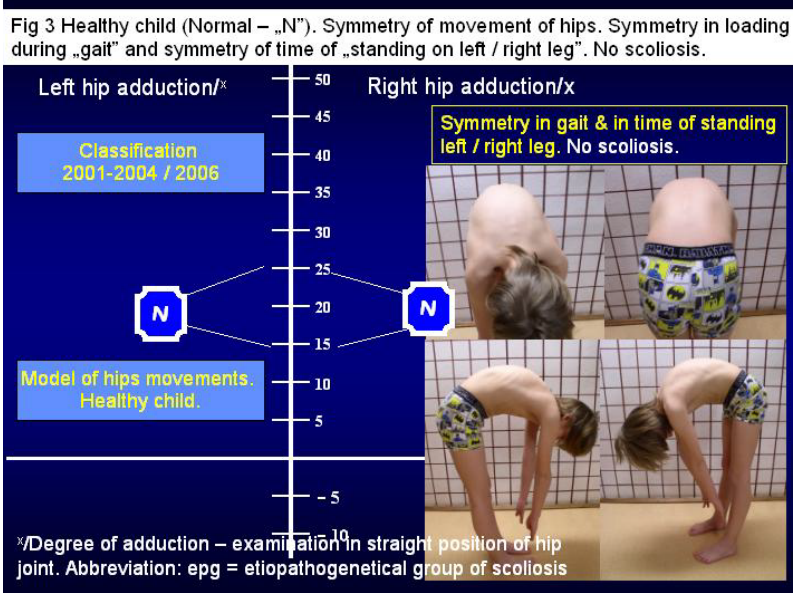

Figure 3. Proper "model of hips movement”-no scoliosis.

four types of scoliosis: "S" double scoliosis-I etiopathological group (epg); causal gait and standing on right leg, lumbar left convex curve in "C"-II/A scoliosis sometimes with secondary thoracic right convex curve in "S"-II/B epg scoliosis; causal standing on right leg. In this subgroup ("S"-II/B epg scoliosis) not only standing "at ease" on the right leg is the cause of scoliosis but also the laxity of joints (typical for minimal brain dysfunction [MBD]) and harmful exercises in former therapy;

7) Gait also plays an important role in one more type of scoliosis. This type of scoliosis manifests itself as stiffness of spine in III epg. This deformity produces no curves or gibbous or a very slight one.

\subsection{Asymmetry in the Movements of Hips}

There are differences in the movement concerning the range of adduction, internal rotation and extension. Types of scoliosis in connection to "the model of hip movements” are presented in Table 1.

\subsection{New Classification of Scoliosis [4-10]}

Every type of scoliosis starts to develop at the age of 2 or 3. 
Table 1. Type of hips movements and adequate type of scoliosis.

\begin{tabular}{|c|c|c|c|c|}
\hline & Scoliosis “ $S$ ” in I epg. & Scoliosis “C” in II/A epg. & Scoliosis “S” in II/B epg. & Scoliosis “I” in III epg. \\
\hline & $\begin{array}{l}\text { Two curves. Gibbous. } \\
\text { Rigid spine. 3D }\end{array}$ & One curve. 1D & $\begin{array}{l}\text { Two curves. Gibbous mild and } \\
\text { round. Flexible spine. } 2 \mathrm{D} \text { or mix }\end{array}$ & $\begin{array}{l}\text { Only stiffness of spine. } \\
\text { No curves and gibbous } \\
\text { or small ones 2D or mix }\end{array}$ \\
\hline $\begin{array}{l}\text { First type of } \\
\text { "hips model } \\
\text { movement" }\end{array}$ & $\begin{array}{l}\text { Right hip adduction } 0(-5) \\
\text { or }(-10) \text { degree } \\
\text { Left hip adduction degree } 35 \\
\text { or } 40 \text {, or } 50 \text { degree }\end{array}$ & $\mathbf{4}$ & & $\boldsymbol{4}$ \\
\hline $\begin{array}{l}\text { Second type of } \\
\text { "hips model } \\
\text { movement" }\end{array}$ & & $\begin{array}{l}\text { Right hip adduction } 15 \text { or } 20 \text {, } \\
\text { or } 30 \text { degree } \\
\text { Left hip adduction } 35 \text { or } 40 \text {, } \\
\text { or } 50 \text { degree }\end{array}$ & $\begin{array}{l}\text { Right hip adduction } 15 \text { or } 20 \text {, } \\
\text { or } 30 \text { degree } \\
\text { Left hip adduction } 35 \text { or } 40 \text {, or } \\
50 \text { degree plus laxity of joints } \\
\text { or/and harmful exercises before }\end{array}$ & \\
\hline
\end{tabular}

1st etiopathological group of scoliosis is "S" deformity in I epg (Table 1). This scoliosis can be diagnosed very early, at the age of 3 to 5 . The authors observed that children aged 1 year who can walk and stand independently, stand mostly "at ease" on the right leg (observation in Out-Patient Clinic of both authors) and it should be an alarming sign for doctors and parents indicating the beginning of the developing of scoliosis. In the I epg group, the first clinical sign is the rotation deformity which should warm against future spinal deformity. In some cases of I epg group, there is "lordo-scoliosis". The property of such scoliosis is: progression, especially after harmful exercises (Figure 4).

2nd etiopathological group of scoliosis-"C" II/A epg deformity and "S" II/B epg deformity (2001). The scoliosis in II/A epg or II/B epg can be diagnosed at the age of $8-10-12$ (Table 1 ). The cause is the habit of permanent standing "at ease" on the right leg for many years. Initially, it is the physiological deviation, then "C" left convex curve. In the development of the "S" II/B epg scoliosis, there occurs additionally laxity of joints and/or harmful exercises. In some cases of II/B epg group, we observe kypho-scoliosis (Figure 5).

3rd etiopathological group of scoliosis (2004) - ScOliosis with little or no curvature (Table 1). The cause is connected only with gait. In gait due to a restricted movement in the right hip, and a small movement in the left hip, a compensatory rotation movement in the spine is created. This compensatory movement makes, as mentioned above, a permanent distortion in the inter-vertebral joints which result in stiffness and rigidity of the whole spine. The stiffness of the spine can be observed in youth. However to date, nobody considered this to be scoliosis. These patients when adult often suffer from back pain (Figure 6).

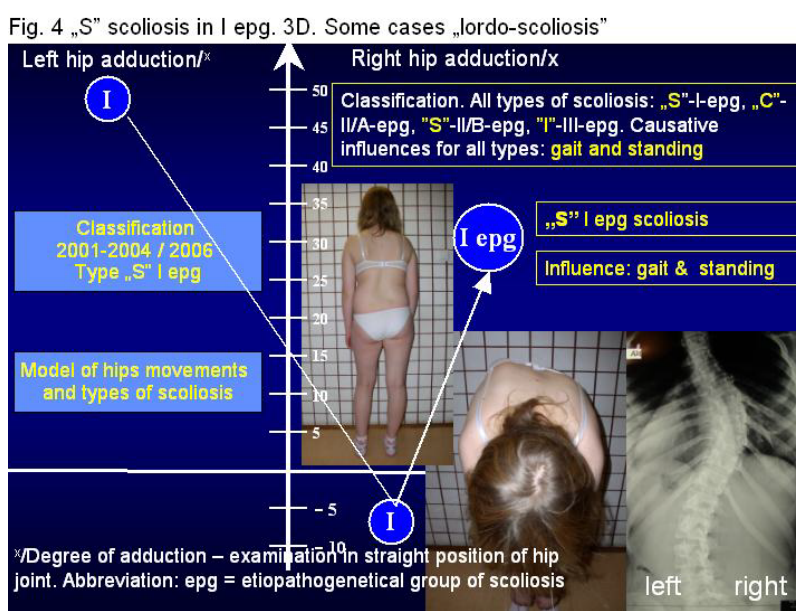

Figure 4. Scoliosis in I epg with double curves, gibbous on the right side, stiff spine. $3 \mathrm{D}$. There is a connection with gait and standing on the right leg and with the adequate model of hip movements.

Short information about new tests in screening of scoliosis.

List of the new tests and questions to recognize an early stage of scoliosis:

1) Test of adduction of both hips (in extension position of the joints-like the Ober test). It also checks the flexion contracture of the hips and the external rotation contracture of the right hip;

2) Bending test for scoliosis-Adams/Meyer test. Flexion test performed with bent spine (and the whole body). If the shape is round it is good, if stiff and straight, it shows the beginning of scoliosis. The disappearance of processi spinosi in thoracic part Th 7 - Th 12 in very early stage of the development of scoliosis is frequently observed;

3) Side bending test for scoliosis (bending to the left 


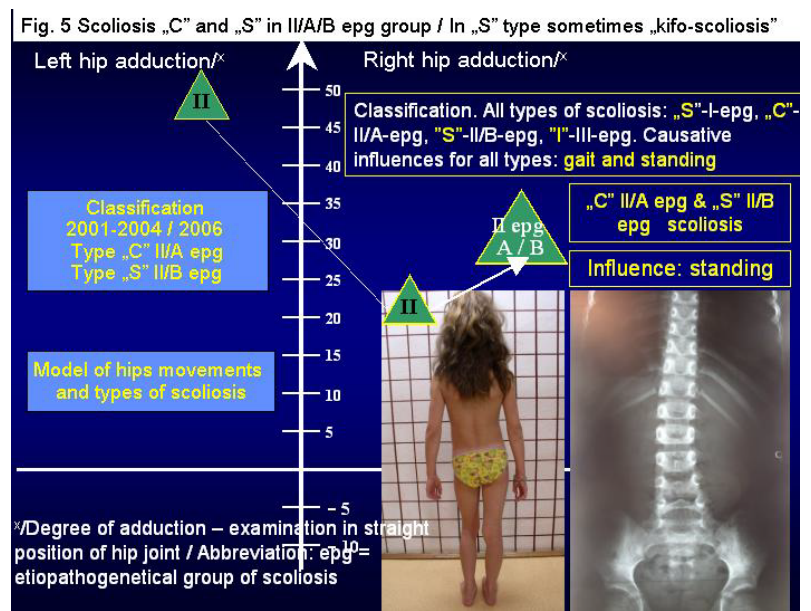

Figure 5. Scoliosis in II/A epg and in II/B epg. One curve scoliosis- "C" II/A epg. 1D, or double curves scoliosis- " $S$ " II/B epg. 2D. Flexible spine. There is a connection with standing on the right leg (II/A epg) accompanied by laxity of joints or/and wrong therapy (II/B epg). There is a connection with adequate model of hip movements.

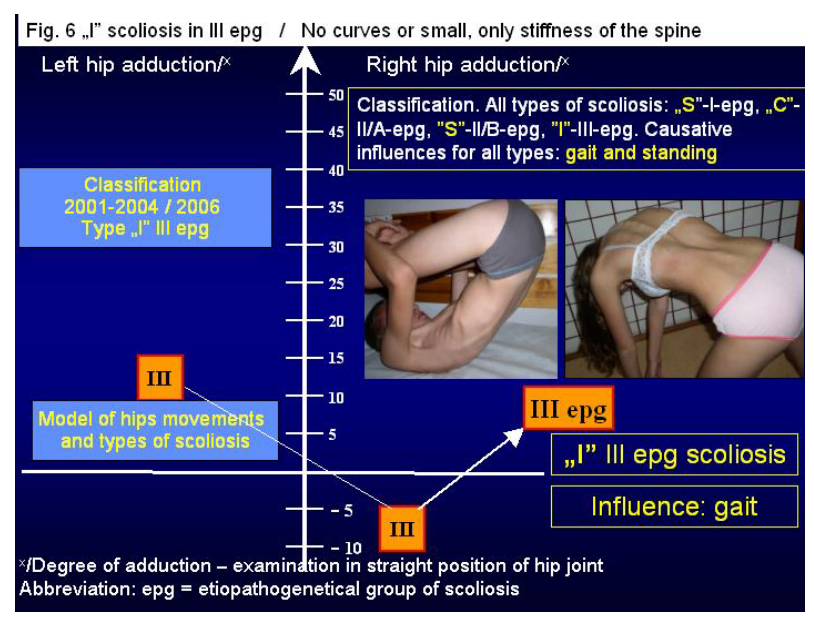

Figure 6. Scoliosis in III epg. 2D or 3D. It is characterized by rigid spine only. There are no curves or gibbous or a very slight one. There is a connection with gait only and with the adequate model of hip movements.

and to the right leg during standing in abduction), also called Lublin test. It is a modified Adams/Meyer testmore sensitive than Adams test;

4) Rotation movements of the body test- - to left and to the right (new test introduced in 2006) performed in standing position of the child;

5) Permanent standing "at ease" test-it checks the habit of standing on the right versus the left leg. In scoliosis patients stand only or mostly on the right leg;

6) The symmetry or asymmetry of the waist test (an old test, but still very important);

7) Presence of rickets. Rickets may initiate the onset of scoliosis;

8) Presence of other deformities such as spina bifida occulta, pectus infundibuliforme, etc. If present, the proper development of the spine is endangered;

9) Body build type — asthenic and picnic (bad), athletic (good);

10) Willingness to participate in sports, if yes-good, if no-bad (Figure 7).

Short information about new exercises in prophylaxis and in treatment.

Below the general outline for the new rehabilitation exercises is presented (Figure 8). Firstly, it must be underlined that all extension exercises (that is the so-called strengthening exercises) were and still are wrong and harmful. All patients coming to our department after such previous therapy suffered from huge deformities, bigger humps and stiffness of the spine. To explain these undesirable results of the treatment the term "the natural history of scoliosis" was coined. In our opinion, the proper solution for the spinal problem is an early prophylactics based on the biomechanical etiology of scoliosis. This new therapy must be based on the new exercises which are beneficial both for the treatment and the prophylaxis of scoliosis. They include all exercises removing contractures in the region of the hips, of the pelvis and in the spine such as flexion-rotation exercises practiced as early in life as 3 or 4 . All relaxation exercises which remove abduction, external rotation and flexion contracture of the right hip, as well as all exercises removing contracture on the concave side of curves are very useful. Additionally, it is important to stand on the left leg instead of the right when "at ease", to relax and sleep in foetal position and to practice sport, especially involving stretching (for example karate, taekwondo, aikido, yoga and other).

\section{The Results}

The results of causal prophylaxis ere excellent which means that the spinal deformity can be stopped or diminished when proper prophylactic exercises are introduced early enough, that is at the age of 3, 4 or $5 \mathrm{y}$. As described in previous articles [4-10] $93 \%$ of children with all types of scoliosis-I epg, II/A epg and II/B epg had positive results, namely: the progression stopped, in other cases deformity diminished (curves and gibbous), the global functioning of the body improved. Only $7 \%$ of children, previously treated for some months or years with the wrong and harmful exercises, showed no correction. Prophylaxis must start at the age of 3 - 5. This article shows two cases-one treated with the wrong harmful exercises (Figures 9(a)-(e)), the second case shows sufficient good result after proper exercises. These were stretching exercises for the spine and for hips and pelvis. After 2 years of new therapy, the curve diminished. Cosmetically result good (Figures 10(a)-(c)). 


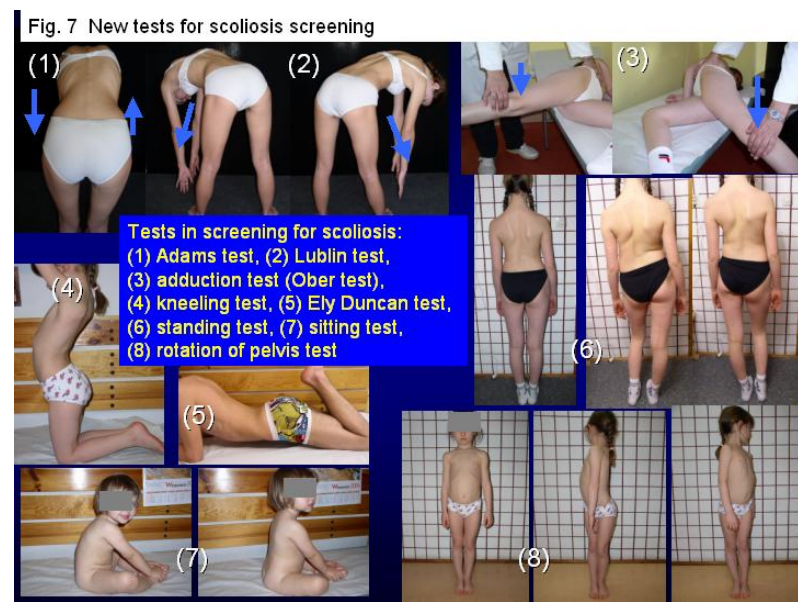

Figure 7. New test in the screening of scoliosis.

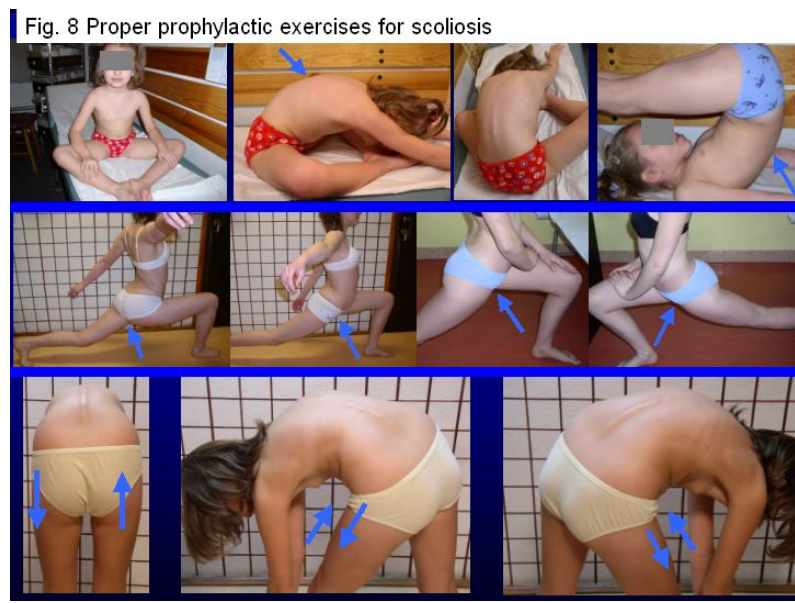

Figure 8. New exercises in scoliosis.

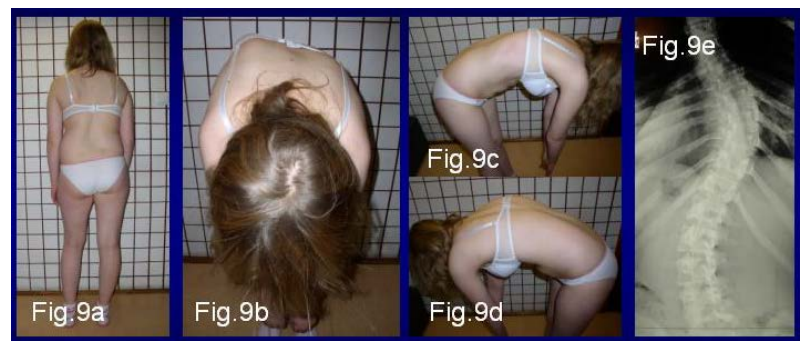

Figure 9. The child treated incorrectly (prior to contact with the authors). Harmful exercises were performed for five years. In result the deformity of trunk and spine. The girl is unhappy and unable to do sport. In 2013, patient start to do new exercises.

\section{Conclusions}

1) Last 28 years of Lublin observations confirmed the biomechanical etiology of scoliosis;

2) There are three types and four groups of scoliosis connected with causative influence "standing on the right leg at ease" (next treated as "standing") and with "walking" (gait);

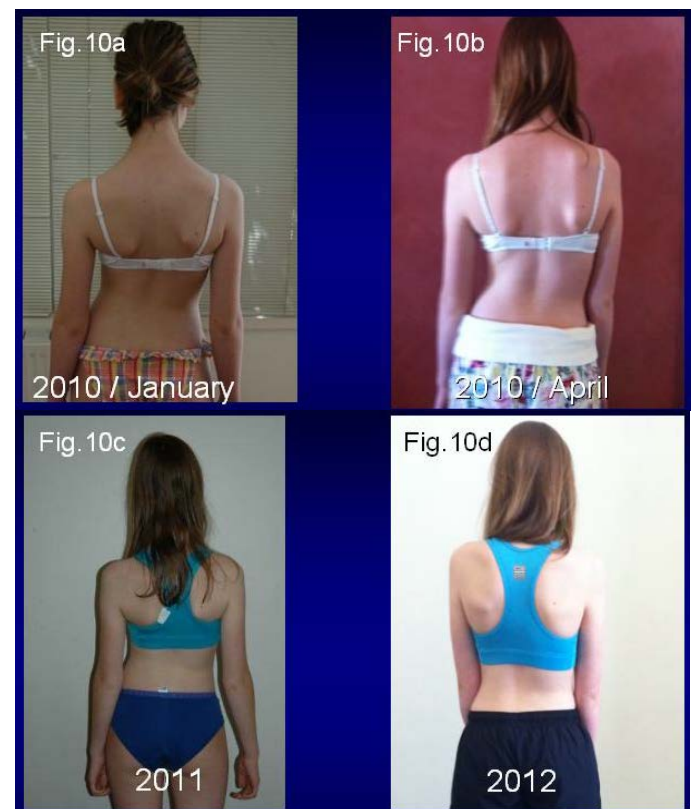

Figure 10. Patient at the time of the first appointment (April 2010) with the authors present a developed scoliosis. After doing new, proper exercises the progression is stopped. Now (2012), after 2 years of new therapy diminishing of thoracic curve is visible. Results cosmetically are good. Patient actively every day does sport. She and her family are happy.

3) There are following types of scoliosis: a) "S" I epg, 3D. Causative influence: standing and gait, b) "C" II/A epg, 1D. Causative influence: standing, c) "S" II/B epg, 2D or mix. Causative influence: standing, plus laxity of joints and/or incorrect exercises in previous therapy, d) "I" III epg, 2D or mix. Causative influence: gait;

4) Each type of scoliosis starts to develop in age of 2 3 years;

5) Both the old tests (Adams \& Meyer test) but also the new tests should be used for early screening. The new tests include: Lublin- “side bending test”, checking for the habit of standing "at ease" (right versus left leg), Ely Duncan test (or Thom or Staheli test), adduction of hips test (Ober test), and other (described above);

6) In the course of treatment and prophylaxis of the hips and spine, the following should be introduced: stretching exercises, typical for karate, kung fu, taekwondo, aikido, yoga. All these exercises prove to be very beneficial for "mal position of body" and for scoliosis. Children endangered with scoliosis should stand more on left leg, should sit relaxed and sleep in foetal position. They should performed, as mentioned above, actively sport.

\section{Acknowledgements}

I would like to express my many thanks to Katarzyna Karska MA for her help to correct the text. 


\section{REFERENCES}

[1] N. E. Green and P. P. Griffin, "Hip Dysplasia Associated with Abduction Contracture of the Contralateral Hip," The Journal of Bone \& Joint Surgery, Vol. 64, No. 9, 1982, pp. 1273-1281.

[2] R. N. Hensinger, "Congenital Dislocation of the Hip," Clinical Symposium, 1979, p. 31.

[3] B. Howorth, "The Etiology of the Congenital Dislocation of the Hip,” Clin. Orthop., Vol. 29, 1977, pp. 164-179.

[4] T. Karski, "Etiology of the So-Called 'Idiopathic Scoliosis'. Biomechanical Explanation of Spine Deformity. Two Groups of Development of Scoliosis. New Rehabilitation Treatment. Possibility of Prophylactics, Studies in Technology and Informatics, Research into Spinal Deformities 4,” IOS Press, Amsterdam, Berlin, Oxford, Tokyo, Washington DC, 2002, pp. 37-46.

[5] T. Karski, "Explanation of Biomechanical Etiology of the So-Called Idiopathic Scoliosis (1995-2007). New Clinical and Radiological Classification,” Pohybove Ustroji (Locomotor System), Vol. 17, No. 1-2, 2010, pp. 26-42.

[6] T. Karski, "Biomechanical Etiology of the So-Called Idiopathic Scoliosis (1995-2007)_Connection with 'Syndrome of Contractures'-Fundamental Information for Paediatricians in Program of Early Prophylactics,” Journal of US-China Medical Science, Vol. 8, No. 78, 2011.

[7] K. Tomasz, "Factores Biomechanicos en la Etiologia de las Escoliosis Dinominadas Idiopaticas. Nueva Classificacion. Nuevos Test Clinicos y Nueavo Tratamento Conservador y Profilaxis," Cuestiones de Fisioterapia, Vol. 39, No. 2, 2010, pp. 144-152.
[8] K. Tomasz, "Biomechanical Etiology of the So-Called Idiopathic Scoliosis (1995-2007). New Classification: Three Groups, Four Sub-Types. Connection with Syndrome of Contractures," The Pan Arab Journal of Orthopaedics and Trauma, Vol. 14, No. 2, 2010.

[9] K. Tomasz, "Biomechanical Etiology of the So-Called Idiopathic Scoliosis (1995-2007). Three Groups and Four Types in the New Classification," Journal of Novel Physiotherapies, S2, 2013, 6 p.

[10] K. Jacek and T. Karski, "So-Called Idiopathic Scoliosis. Diagnosis. Tests Examples of Children Incorrect Treated. New Therapy by Stretching Exercises and Results," Journal of Novel Physiotherapies, OMICS Publishing Group, USA, 3-2, 2013, 9 p.

[11] M. H. Zur, “Ätiopathogenese von Skoliose, Hüftdysplasie und Schiefhals im Säuglinsalter," Zeitschrift f. Orthop., Vol. 5, 1979, pp. 601-605.

[12] M. H. Die, “Atiopatogenese der Skoliose, Bücherei des Orthopäden, Band 33,” Enke Verlag Stuttgart, 1982, pp. 1-110.

[13] H. Normelly, "Asymmetric Rib Growth as an Aetiological Factor in Idiopathic Scoliosis in Adolescent Girls," Stockholm, 1985, pp. 1-103.

[14] J. Sevastik and K. Diab, "Studies in Technology and Informatics, Research into Spinal Deformities 1,” IOS Press, Amsterdam, Berlin, Oxford, Tokyo, Washington DC, 1997, pp. 1-509.

[15] www.ortopedia.karski.lublin.pl 